April 29th, 1890. Her mother stated that for ten weeks the patient had been suffering from chorea. The movements had been most marked in the upper extremities and the tongue, but scarcely noticeable in the lower limbs. About a fortnight before bringing the child she noticed a deformity of the right hip-joint, with bending and shortening of the limb. The child cried when touched or moved, but was free from pain when left at rest. There had been no "starting" at night. At the beginning of her illness there was swelling, heat and pain in the left ankle and knee-joints. No record of temperature observations was obtained. On examination the child was found to be very anæmic and emaciated. She lay with her right thigh adducted and slightly flexed on the abdomen, the knee semi-flexed and the foot inverted; there was marked sbortening and the trochanter was one inch above Nelaton's line In fact, she presented the classical signs of dorsal dislocation of the hipjoint. Gentle attempts to straighten or manipulate the limb gave great pain. With the exception of a loud systolic murmur at the apex of the heart, which was conducted to the axilla and clearly organic, no other physical signs were evident. There were no choreic movewents. Chloroform was administered by Dr. Arthur Rowe, and no alteration was observed in the deformity. Reduction was easily effected by manipulation and a long outside splint applied. The subsequent history of the case was simple. The child's general health rapidly improved; the splint was removed in three weeks, and the joint was found to be healtby and freely movable. Four months later the father wrote that the child was "quite well sare for a slight stiffness."

Cases of dislocation occurring in the course of acute rheumatism are so rarely recorded that it may be well to emphasise the salient features in this case. That it was a true dislocation is evidenced by the shortening, flexion and inversion of the limb and by the other marked signs of luxation, by the persistence of these conditions under chloroform, by the immediate restoration of the limb to its proper form by operation and by its rapid and complete recovery. That the child had suffered from acute rheumatism seems clear from the history of pain and swelling of the joints, followed by an attack of chorea, endocarditis and marked anæmia. The mechanism of the occurrence is not quite clear, but it is probable that a certain amount of effusion occurs into the synovial cavity accompanied by inflammatory softening and stretching of the ligaments, resulting in displacement of the head of the femur; or, as was suggested in an annotation in THe LANCET, " "it may be that owing to the diseased state of the joint the customary co-crdinate support of the muscles is wanting, and that as a result of the inordinate action of a certain group of muscles wl en the limb is in a 'vicious' attitude the dislocation may be brought about." I have been able to trace few similar cases; the most noteworthy are recorded by Stanley ${ }^{2}$ in England and by Brown ${ }^{3}$ in America. I he annotation in THE LANCET referred to above mentions seven cases recorded by M. Verneuil at the Société de Chirurgie, but gives no details. Ethelbert-terrace, Margate.

\section{SQUAMOUS EPITHELIOMA OF THE EXTERNAL EAR}

BY W. S. CRawford, B.A. Cantab., F.R.C.S. Edin., ASSISTANT SUIGEON, LIVERPOOL CANCER AND SKIN HOSPITAL.

IHE following case appears to be worth recording on account of the comparative rarity of the affection.

The patient from whom the growth was removed was a man aged sixty-four. He first noticed fourteen months ago a small wart in the upper part of the fossa of the helix. This increased very gradually in size until about seven month since, when he received a blow on the side of his head from a cow's tail which caused the warty growth to bleed. After this time it grew more rapidly and spread over to the back part of the ear; it often bled and discharged matter continuously, which, decomposing, gave rise to extreme fetor. When he came under my notice recently the whole of the external ear except the concha and lobule appeared to be composed of an irregular soft warty growth, smeared over with fetid pus and a few small blood-clots. The mass averaged an inch in thick ness, there was very little deep ulceration, and the tumour was particularly soft and papillomatous in character. The growth

1 The Lancer, vol. ii. 1883, p. 919

2 Mediral and Chrurgical Transactions, 1841, p. 132

Boston Medical Journal, Sept. 29th, 1870 . was removed by simply slicing the ear off, leaving only the deeper part of the concha, the antitragus and the lobule; no enlarged lymphatic glands could be felt. A microscopical examination of the specimen was made by my friend $\mathbf{M r}$. Thelwall Thomas. 'The sections showed well-marked squamous epithelioma.

Mount Pleasant, Liverpool.

\section{SENSITIVENESS OF THE PERITONEUM.}

BY T. R. Jessop, F.R.C.S. ENG,

CONSULTING SURGEON TO THE LEEDS GENERAL INFIRMARY.

HAving occasion a few days ago to perform inguinal colotomy, I asked Mr. Moynihan, our resident surgical officer, to test the sensitiveness of the exposed peritoneum so soon as the patient should have completely recorered from the anæsthetic. Mr. Moynihan informs me that he pricked, scratched, and handled the exposed bowel (which appeared to be in no way altered from its normal condition), with the result that the patient declared her sensation was as if she were being "lightly touched with a feather." A similar result was obtained from like tests applied to the turned-up edge of the parietal peritoneum. At the same time the patient felt acutely the prick of a pin applied to the skin in the neighbourhood of the wound and elsewhere.

Palk-square, Leeds.

\section{a}

\section{HOSPITAL PRACTICE, BRITISH AND FOREIGN.}

Nulla autem est alia pro certo noscendi via, nisi quamplurimas et mor. porum et dissectionum historias, tum aliornm tum proprias collecta porum et dissectionum historias, tum aliornm tum proprias collectas
habere, et inter se comparare.-MokgaGNI De Sed. et Carus. Morb., lib. iv. Procemium.

ST. THOMAS'S HOSPITAL.

TREATMENT OF THE ULCERATIVE LESION IN LARYNGEAT, TUBERCULOSIS, WITH SOME REMARKS ON THE CONSTITUTIONAL TREATMENT BY LARGE DOSES OF CREASOTE.

(Under the care of Dr. F. SEMON.)

THE following cases of laryngeal, coupled with pulmonary, tuberculosis are quoted to show the effect produced by the internal administration of creasote in large doses and the energetic application of lactic acid locally. No case is reported that had not characteristic lung symptoms, so that we can safely assume all the lesions were truly tubercular. It is absolutely essential that the creasote be perfectly pure, as otherwise it may cause dyspepsia, but in estimating the action of the drug we must not forget the frequency of that symptom in phthisis. It must be given immediately after meals and on no account whatever when the stomach is empty. It is taken either in pills or capsules containing one minim of creasote; but so long as the creascte is pure, either are equally efficacions. At first one minim after meals three times a day is given; then, after a day or two, two minims and the dose is slowly increased until the patient is taking nine, twelve or even fifteen minims per diem. The solutions of lactic acid used are in the strength of $20,30,40,50,60$ and 70 per cent., which are also gradually increased according to the toleration of the larynx and the necessities of the case. In most cases it is not necessary to employ solutions stronger than 40 to 50 per cent. It is applied two, three or four times a week, as the case requires, and refore every application the larynx is well brushed with a 20 per cent. solution of cocaine. After a few minutes the acid is applied on absorbent wool firmly wrapped round rectangular laryngeal forceps. It must be rubbed into the u'cerating part with a vely fair amount of force, so that the breaking-down tissue is removed and the acid comes into direct contact with the floors of the ulcers. Just as in a tuberculous joint the diseased tissue is forcibly scraped, so must the larynx be treated; and herein lies the great advantage of firm forceps 
over a brush or pledget of wool. In cases where there is much cedema, it must first be allowed to subside and inhalations or insufflations of sedatives are to be preferred. It is needless to say that tho application must be made under the guidance of the laryngeal mirror, not only because this affords the only certainty that the diseased parts are actually reached, but also because the forcible application of such strong lactic acid solutions to hitherto unaffected parts would be anything but an indifferent measure. In cases in which, in addition to ulceration, there is abundant granulation tissue it may be necessary, previously to the application of the lactic acid, to scrape away the granulations by means of Heryng's or Krause's laryngeal curette. For the following account we are indebted to $\mathrm{Mr}$. Marcus A. Dorman, clinical assistant to the throat department.

CAsE 1. Ulcerating swelling in inter-arytenoid fold; left cord hidden by granulation tissue; left arytenoid snollen.-A woman aged twenty-five.

June 20th.-Lungs: Left apex, impairment of resonance and some moist sounds. Two minims of creasote were ordered three times a day and the application of a 30 per cent. lactic acid solution twice a week.

July 21st. -All ulceration has disappeared; there is slight granulation tissue on the left ventricular band, but the cord is visible throughout its entire length; the voice is stronger and clearer.

The patient left for India on Aug. 6th, and wrote in October saying that she was still taking capsules, which caused no disagreeable effects. A medical man had examined her throat and stated that it was well. Her cough was much less troublesome and she slept well at night. The patient was then taking nine minims a day.

This case was fortunately treated at a very early stage and was rapidly relieved.

CASE 2. Snelling and ulceration in inter-arytenoid fold \&c.A woman aged twenty-seven; occupation housework; weight 9 st. 31 b.

Oct. 20th.-Lungs : Impairment of resonance of the right apex, but no crepitations, bæmoptysis, night sweats, anæmia, voice weak and hoarse. A 20 per cent. solution of lactic acid was ordered twice a week and two minims of creasote three times a day.

Nov. 17th. - There is less ulceration; ordered nine minims of creasote daily.

Dec. 1st. - Lactic acid discontinued as no ulceration can be seen; weight 9 st. 10lb. The hæmoptysis has ceased and the voice is clear and stronger.

This is also an early case and the increase in weight argues well for the treatment.

CASE 3. Early ulceration of larynx.-A porter aged thirty-seven.

July 12th. The voice is hoarse. Lungs: There is dulness at the right apes, with tubular breathing; also much cough and expectoration. A 30 per cent. solution of lactic acid was ordered three times a week and creasote.

Oct. 4th. - The ulcers are healed, and there is some granulation tissue on the cords. The lactic acid has been discontinued, but nine minims of the creasote are to be given daily.

Nov. 24th. - The cough is better, and there is less expectoration ; the patient is gaining in weight. There is no lesion in the larynx.

Dec. 15 th. - The voice is normal ; the cords are pink, but no ulceration or granulation tissue is to be seen.

The lungs in this case were consolidated at the apices, but the symptoms were much relieved and the larynx healed.

CAsE 4. IIuch snelling and ulceration on epiglottis; small swelling in inter-arytenoid fold; cords quite hiadden by granulation tissue.- $-\Delta$ man aged fifty-two.

July 15th.- - Lungs : There are signs of extensive cavity in the right upper lobe; cough and expectoration are excessive the voice is very thick and indistinct. The epiglottis was scraped with a curette and a 40 per cent. solution of lactic acid was applied, and a 30 per cent. solution to the interior of the larynx three times a week. Six minims of the creasote were ordered daily.

28th. - Both cords are visible ; the epiglottis is still ulcerating and deglutition is very painful.

Aug. 11th.-There is no ulceration in the larynx, but there is still some on the epiglottis; supervention of melæna. The patient complains that he cannot swallow pills. The lactic acid ordered to be discontinued.

23rd.-There is much swelling of the interior of the larynx. The patient lied on Sept. 2nd from general tuberculosis.
This case was so very far advanced that but little could be done. The ulcers in the larynx healed, but the general disease increased. The inability to take the creasote was very unfortunate.

CASE 5. U.ceration on posterior part of right cord and interarytenoid fold.-Telegraphist aged twenty-seven; weight 8 st. $11 b$.

Oct. 5th.-Lungs : Impairment of resonance, increased vocal resonance and metallic crepitations were audible at the front and back of the right upper lobe. The patient has suffered from hæmoptysis, cough and expectoration for two years. The voice has been thick for seven or eight weeks. A 30 per cent. solution of the lactic acid was ordered twice a week and six minims of creasote daily.

Nov. 11th. - The patient has not attended for three weeks and has not taken the creasote. There are much swelling and ulceration of the larynx and of the arytenoids, so that deglutition is impossible. The throat was painted with cocaine before each meal, which consisted of a pint of milk and two eggs beaten up in it. In three days the swelling had disappeared, and a 50 per cent. solution of the lactic acid was applied, whilst twelve minims of creasote were ordered daily.

24th. - The patient is much better. There is no ulceration and the weight is 8 st. $10 \mathrm{lb}$.

The increase of weight here is a proof of the amelioration of the patient's condition. It also illustrates the advantages f such a great excess of fats and proteids-i.e., ten ounces of proteids and fifteen ounces of fat-in enfeebled constitutions.

CASE 6. Deep excavating uleer on epiglottis; arytenoids swollen and ulceration in inter-arytenoid fold; voice feoble but clear.-A plumber aged forty-one. The patient attended at Bromptom Hospital in July, 1885, under Dr. Acland. The notes of the case then were: "Hæmoptysis sixteen weeks, with cough and expectoration ; losing weight."

June 22nd, 1892. - There were signs in both lungs, chiefly in the right. A 20 per cent. solution of the lactic acid was ordered to be applied twice a week and two minims of creasote to be taken three times a day.

July 6th. - The ulcer on the epiglottis was cicatrised. A 40 per cent. solution of lactic acid was ordered and three minims of creasote three times a day.

21st. - There is no ulceration in the larynx. The patient complains of pain shooting down the right side of the neck. He left London for Dover, and discontinued the creasote.

Sept. 4th. - His general condition is worse. There is a white swelling under the anterior part of both cords. There are no ulcers.

Oct. 1st.-He was admitted to hospital, and lactic acid has been continued as required, a 70 per cent. solution frequently being used; bis voice is stronger.

Jan. 17th, 1893.-There is no ulceration, but he suffers from pain shooting to the ear, which seems to be temporarily relieved by strong solutions of lactic acid but resists the insuflation of morphia.

This case is undoubtedly slowly progressing, but the immense relief afforded by the lactic acid in deglutition is sufficient warrant for including it here.

CASE 7. Great swelling of epiglottis, nhich is covered with semi-transparent nodules and granulation tissue; both arytenoids enlarged, so that the cords are only just visible; abundant muco-purulent secretion; voice almost lost. -A shopman aged twenty-nine.

Nov. 15th. - Lungs: There are signs of cavity at the left apex. A 30 per cent. solution of the lactic acid was ordered three times a week, and two minims of creasote three times a day.

Dec. 7th. - The creasote was increased to three minims three times a day.

Dec. 15th. - The larynx is free from secretion and there are no ulcers to be seen.

Jan. 13th, 1893. - The general health of the patient is im. proved, he is less anæmic, and the swelling of the larynx has decreased.

This case presented great difficulty in inserting the forceps owing to the extreme swelling of the arytenoids.

CASE 8. Small ulcerating snelling of inter-arytenoid fold.A warehouseman aged twenty-seven.

Oct. 18th. - Lungs : Crepitations are to be heard at the left apex. One minim of creasote was ordered three times a day and a 20 per cent. solution of the lactic acid twice a week.

Dec. 6th. - No ulceration is to be discerned in the larynx. Jan. 3rd, 1893. - The patient has been in Brompton Hospital 
for six weeks. His cough is better, there is less sputum and no ulceration.

This was an early case; the ulcers soon healed.

Remarks by Dr. SEMon. - The above cases illustrate the method of treatment of pulmonary tuberculosis accompanied by laryngeal ulceration which has been practised for the last few years at the Throat Department of St. Thomas's Hospital. 'This method certainly is a great step in advance upon all the previous modes of treatment recommended during the last ten or fifteen years, and to which a trial has been given in the department. It will of course be understood that the constitutional treatment by large doses of creasote cannot claim in any way, so far as my experience is concerned, to be looked upon as a true specific against tuberculosis, but it can be positively stated from a large experience both in hospital, and even more in private practice, in which the patients more strictly attend to their health, that as a symptomatic treatment it excels every other form at present known. The patients gain in weight, their appetite improves, the night sweats diminish, the expectoration becomes less purulent, and in a good many cases, especially if not coming under observation at too late a period, the disease actually appears to become arrested. Such, at any rate, has been the case in several instances in my private practice, in which I hare had the opportunity of watching the patients for periods of two or three years, during which some of them have taken up to 10,000 creasote capsules. Only in very rare instances patients cannot digest the creasote in such large doses, and I would especially warn against looking upon every occasional indigestion as an indication to the effect that the creasote treatment must at once be given up. But it is absolutely necessary, first, that the creasote preparation should be perfectly pure, and, secondly, that the capsules or pills be taken immediately after meals. Concerning the lactic acid treatment of the laryngeal complication, this, too, is a purely symptomatic one, and cannot claim to "cure" the Jaryngeal disease. Considering, however, how much laryngeal ulcerations, by producing pain, cough and dysphagia, contribute towards hastening the fatal end, any relief to these three serious symptoms is a distinct gain, and it can certainly be said of the lactic acid treatment, as described above, that it surpasses all methods previously recommended in attaining within a comparatively short time, and for a longer period than any other method known to me, the desired effect.

\section{SOUTH DEVON AND EAST CORNWALT HOSPITAL, PLYMOUTH.}

PAROTITIS FOLLOWING INJURY TO THE ABDOMEN.

(Under the care of Mr. PAuL SwAIN.)

Ir this case the inflammation of the parotid gland was soticed three weeks after the occurrence of an injury to the abdomen, the nature of which was uncertain. It is a point worthy of note that the severe vomiting ceased when the inflammation of the parotid gland was at its height, and convalescence rapidly followed. The close relationship which exists between the parotid gland and the contents of the abdomen is again exemplified in this case. Our readers will remember the paper on this subject by Mr. S. Paget." He found that out of 101 cases 10 followed injury or disease of the urinary tract; 18 of the abdominal wall, subperitoneal or pelvic cellular tissue or peritoneum ; 50 followed injury, disease or temporary derangement of the generative organs. In 93 out of the 101 cases it was an isolated event, not pyrmic. For the notes of this case we are indebted to Mr. Stanley Thomas, house surgeon.

A child aged eleven years on Oct. 21st, 1892, fell from a pony, injuring her left leg and shaking herself severely. She was admitted to hospital on the 26 th, and was found to be suffering from a separation of the lower epiphysis of the left femur. On the 27th she began to vomit. The bowels had not been opened since the day of the accident. The next day she still vomited frequently. The bowels were opened after an enema. On the 31 st she seemed better, and was able to take milk and lime-water. On Nov. 6th she began to vomit again, and on the following day the sickness was very severe and the child looked extremely ill. The tongue was very dry and the abdomen very retracted, except in the epigastric region, where there were some fulness, great tenderness and dulness on percussion. The temperature was $99.8^{\circ}$ and the pulse very feeble. The child had become emaciated during the past few days. She was fed by nutrient enemata. On the 9 th she continued to vomit large quantities of dark-green fluid, vomiting as much as from eight to ten ounces at a time. Or the 11th slight swelling and great tenderness were noticed in the region of the left parotid gland, to which fomentations were applied. The next day the parotid was very swollen and looked as if it would suppurate. On the 14th the sickness had stopped. The patient was then taking peptonised milk.

Nov, 24th. - The child has not suffered from sickness since the 14 th ; there is no tenderness across the abdomen ; the dulness has gone and the inflammation of the parotid has quite subsided. The patient left the hospital on Dec. 9 th quite well.

\section{attevical Sortities.}

\section{MEDICAI SOCIETY OF LONDON.}

Annual General Meeting.-Supra-pubic Prostatectomy.

THE annual general meeting of this Society was held on March 6th, the President, Mr. Hutchinson, in the chair.

The annual report of the Council was submitted, together with statements from the treasurer and honorary librarian. The financial position was stated to be very satisfactory, and the number of Fellows had considerably increased during the past year. The Fothergillian Medal and Honorary Premium were awarded to Dr. W. R. Gowers for his Contributions to Practical Medicine, and in especial recognition of his work on Diseases of the Nervous System. The following officers were elected for the ensuing year :--President: Dr. John Syer Bristowe. Vice-Presidents: Dr. F. de Havilland Hall, Dr. F. T. Roberts, Mr. D. H. Goodsall and Mr. F. Treves. Treasurer: Mr. A. E. Durham. Librarian: Dr. W. H. Allchin. Honorary Secretaries : Dr. W. Pasteur and Mr. C. B. Lockwood. Honorary Secretary for Foreign Correspondence: Dr. Heinrich Port. Council : Dr. W. Collier (Oxford), Dr. C. J. Cullingworth, Dr. T. Colcott Fox, Dr. A. E. Garrod, Dr. Gerald S. Harper, Dr. G. A. Heron, Dr. Stephen Mackenzie, Dr. E. D. Mapother, Dr. H. Montague Murray, Dr. Samuel West, Mr. H. F. Bailey, Mr. C. A. Ballance, Mr. G. Buckston Browne, Mr. J. Cahill, Mr. F. Swinford Edwards, Mr. J. Hutchinson, Mr. A. Cooper Key, Mr. A. Marmaduke Sheild, Mr. G. R. Turner, and Mr. W. Whitehead (Manchester).

Mr. Buckston Brow Ne read a paper on Supra-pubic Prostatectomy. He began by pointing out that surgically the prostate must be considered as one single organ : its division into lobes was purely arbitrary. It was a sexual organ and only became concerned in the function of micturition when it became hypertrophied or enlarged. Chronic prostatic hypertrophy was (1) intra-vesical, (2) extra-vesical, or (3) both intra-and extra-vesical. The intra-vesical enlargement was the chief cause of difficulty in micturition. This intra-vesical growth was often like an egg projecting into the bladder, with the vesical urethral orifice at the apex of the egg. This ovoid projection might be deficient at any part of the urethral circumference. When wanting anteriorly and laterally, there was the so-called middle lobe enlargement, where from behind the urethral orifice there was a projecting prostatic mass acting like a bullet valve and often causing the bladder to be entirely dependent upon the use of a catheter for the voidance of its urine. More rarely the ovoid projection was only wanting in front, or it might be only on one side; in such cases it was nearly always continuously combined with a posterior enlargement; whilst so rarely as practically to be never met with, the intra-vesical growth was only found anteriorly to the urethral orifice. Intravesical prostatic outgrowths might be associated with considerable extra-vesical enlargement, and the latter might exist without the former and cause the patient so afflicted to be partially or completely dependent upon his catheter. $\mathrm{He}$ expressed the opinion that the intra-vesical growth alone could be removed with reasonable safety and with a fair prospect of recovery of the power of natural micturition. Without digital examination after supra-pubic cystotomy, it could only be approximately diagnosed. All urethrometers and the electric endoscope were useless and dangerous, the danger from their use being the likelihood of their causing severe urethral or catheter fever. There were, however, two 